\title{
Regulation of hematopoietic stem cells in the niche
}

\author{
ZHAO Meng $^{1} \&$ LI LinHeng ${ }^{1,2 *}$ \\ ${ }^{1}$ Stowers Institute for Medical Research, Kansas City, Missouri 64110, USA; \\ ${ }^{2}$ Department of Pathology \& Laboratory Medicine, University of Kansas Medical Center, Kansas City, Kansas 66160, USA
}

Received August 16, 2015; accepted September 17, 2015; published online November 11, 2015

\begin{abstract}
Hematopoiesis provides a suitable model for understanding adult stem cells and their niche. Hematopoietic stem cells (HSCs) continuously produce blood cells through orchestrated proliferation, self-renewal, and differentiation in the bone marrow (BM). Within the BM exists a highly organized microenvironment termed "niche" where stem cells reside and are maintained. HSC niche is the first evidence that a microenvironment contributes to protecting stem cell integrity and functionality in mammals. Although multiple models exist, recent progress has principally elucidated the cellular complexity of the HSC niche that maintains and regulates HSCs in BM. Here we introduce the development and summarize the achievements of HSC niche studies.
\end{abstract}

hematopoietic stem cells, niche, regeneration

Citation: Zhao M, Li LH. Regulation of hematopoietic stem cells in the niche. Sci China Life Sci, 2015, 58: 1209-1215, doi: 10.1007/s11427-015-4960-y

\section{The origin of HSC niche}

The concept of "stem cell" with the properties of self-renewal and differentiation potential was first experimentally evidenced by Till and McCulloch using in vivo spleen colony-forming (CFU-S) assay. Using the CFU-S assay, they showed that single cells could yield multilineages and preserve multipotential $[1,2]$. Now we know that CFU-S assay measures mainly progenitors rather than stem cells, but the nature of this assay led to the niche hypothesis proposed by Ray Schofield in 1978. By noticing that CFU-S "stem cells" have less robust reconstitution capacity in irradiated mice compared to cells from BM, he hypothesized the existence of a BM niche that preserves stem cells [3]. Subsequent studies using in vitro methods showed that BM stromal cells might produce hematopoietic cytokines that support HSCs in culture [4,5]. However, the HSC niche concept was not proven in vivo until mouse genetic engineering technology was developed. Two studies using

*Corresponding author (email: lil@stowers.org) mouse genetic models provided the first evidence of specific BM stromal cells (osteoblastic cells and bone lining cells) supporting mammalian HSCs in vivo [6,7]. Another subsequent study identified that vascular endothelial cells also contribute to HSC regulation in vivo [8]. Until now, despite significant progress achieved in identification of cellular and molecular constituents in HSC niche in BM, the HSC niche was incompletely defined and plagued by competing models. This can be partially explained by the heterogeneity of HSCs and the associated complexity of BM microenvironment. This review aims to summarize the progress of HSC niche studies and to examine historical consensus as well as controversy in the field of HSC niche studies.

\section{HSC interacting cells—a proximity principle}

Since HSC niche was originally defined as the cells that form a microenvironment physically holding HSCs in the $\mathrm{BM}$, the most straightforward approach to search for HSC niche is to identify HSC neighboring cells in the BM. However, this strategy suffers from the rarity and indistin- 
guishability of HSCs in the BM. HSCs are a functionally defined population with the properties of long-term self-renewal and the ability to reconstitute all hematopoietic lineages. Although fluorescence activated cell sorting (FACS) technology allows us to identify and isolate HSCs, in vivo imaging HSCs is still technically challenging because the combination of multiple immunofluorescent markers designed for FACS assay is too complex for microscope detection $[9,10]$. Multiple approaches have been taken by different groups in attempting to locate HSCs in BM. HSCs are well characterized for being in the quiescent state which is correlated with their functionality [11-13]. Various methods have been used to search for quiescent cells in the BM, such as 5-bromodeoxyuridine (BrdU) label retaining, GFP-labelled histone (H2B-GFP) retention, and chemotherapy (e.g. 5-fluorouracil, 5FU) resistance. These methods are all based on the principle that quiescent cells are slow cycling cells that tend to retain labeled DNA and are resistant to DNA damage. Interestingly, the quiescent populations were often found close to endosteum (an inner bone surface) in trabecular bone, albeit by different approaches [7,14-16], suggesting that the endosteum forms a niche to maintain quiescent HSC subpopulations. However, this has been challenged by the specificity of the observed populations, given that some mature cells, such as memory lymphocytes, can also retain DNA labeling due to their long life span [17]. Although researchers attempted to include HSC positive markers in label retention studies to improve the accuracy of observed cells, statistical studies were technically challenging. This is because very few cells could be observed in sectioned BM samples and because the nonspecificity of HSC positive markers, such as Sca-1, also expressed in multiple types of stromal cells in BM. To overcome this issue, two groups independently reported that

immunophenotypic, highly purified HSCs tended to locate at the endosteum in postirradiated mice, but were randomly distributed and unstable in non-irradiated mice $[18,19]$. This provided additional evidence for the endosteum zone serving as the HSC niche, but how this severely stressed transplantation model reflects endogenous HSC distribution in homeostasis needs to be further explored. Other groups took yet another approach to locate HSCs in the BM. They simplified the complicated HSC-FACS immunofluorescent markers into a two-color stain, thus enabling researchers to pinpoint endogenous HSCs under microscopy. Recently developed powerful imaging cytometry platform has also made possible comprehensive quantitative analysis of HSC distribution. One group used a combination of HSC positive marker c-kit with negative markers (CD48 ${ }^{-} \mathrm{CD} 41^{-}$Lineage $^{-}$) and found that the observed cells preferentially localized in endosteal zones where micro-vessels were also enriched [20]. However, this study suffered from a major technical challenge in that the combined markers recognized more progenitor cells than HSCs, which renders the group's observation rather nonspecific. Another combination, using positive marker CD150 to stain HSCs and negative markers lineage, CD41 and CD48 to exclude differentiated cells, detected a more enriched HSC population in the two-color staining [8], although CD150 HSCs might have been missed with this approach [21]. In this method, HSCs initially were found more likely to be adjacent to sinusoid. Recently a comprehensive statistical HSC distribution study was conducted with a mathematic model to interpret HSC distribution. Researchers combined whole-mount confocal immunofluorescence imaging techniques with computational modeling and found that quiescent HSCs associated specifically with small arterioles that were preferentially found in the endosteal region in BM. They found that $\sim 15 \%$ HSCs were adjacent to arterioles and $\sim 30 \%$ HSCs were adjacent to sinusoid. However, since the sinusoidal network was dense and almost evenly interspaced in BM, HSCs adjacent to sinusoids were not statistically differentiated from a random distribution of HSCs in BM. The physical association between HSCs (particularly quiescent HSCs) and arterioles was statistically significant [22]. The same statistically significant nonrandom association was also observed in two recent independent studies where both groups found $20 \%$ HSCs directly adjacent to megakaryocytes (MKs), a type of mature blood cell that produces multiple factors to regulate HSC quiescence $[23,24]$. The combination of comprehensive imaging and computational modeling studies highly suggest the existence of independent regulatory roles from different niche cells that contribute to HSC maintenance and functional regulation in the BM.

\section{Identification of HSC regulating cells-a "taking one out" strategy}

The HSC niche has also been functionally defined as cells that prevent stem cells from depletion, thus protecting the host from over-exuberant stem cell proliferation [25]. The HSC niche is also evidenced by the initial in vivo study showing that the increase of trabecular bone and the associated osteoblastic cells led to the increase of HSCs [6,7]. This suggests that osteoblastic cells or other stromal cells from the endosteal region could potentially form a niche to support HSCs. Subsequent studies have suggested that osteoblasts express many factors that promote HSC maintenance [26], including Stem cell factor (also known as SCF, KIT-ligand, KL, or steel factor), C-X-C motif chemokine 12 (CXCL12), angiopoietin 1 and thrombopoietin (THPO) $[14,27,28]$. However, the stromal cell composition of the BM is as complex as its hematopoietic counterpart. Later studies proposed that a perivascular niche (endothelial cells and pericytes) might also produce those factors that contribute to HSC regulation. To directly study how stromal cells contribute to HSC regulation through those niche fac- 
tors, a "taking one out" strategy was performed to specifically delete each factor from different niche cells and study its influence on HSC function.

$\mathrm{SCF}$ is a growth factor that binds to the c-kit receptor (CD 117), a receptor tyrosine kinase that expresses in HSCs at all stages of development [29]. SCF is non-cell autonomously required for HSC proliferation, survival, and function in vivo [30]. Mice that do not express SCF die in utero from severe anemia [30]. To investigate the functional resource of SCF that contributes to HSC regulation, a genetic approach of deleting $S c f$ from multiple niche components was performed. Researchers found that HSC frequency and function were not affected when $S c f$ was conditionally deleted from hematopoietic cells using Vav-1-Cre, from osteoblasts using Col2.3-Cre, and from Nestin-expressing cells using Nestin-Cre or Nestin-Cre/ERT2. However, HSC number was largely reduced from bone marrow when $S c f$ was deleted from Tie-2-Cre marked endothelial cells or leptin receptor (Lepr)-expressing perivascular stromal cells [31]. This study proposed that endothelial and Lepr-expressing perivascular cells are a critical source of SCF that contributes to HSC regulation in the BM.

The CXCL12, also known as stromal cell-derived factor 1 (SDF-1), is a chemokine, which is an important regulator of leukocyte and hematopoietic precursor migration [32] along with G-CSF-induced HSC mobilization [33]. Deletion of CXCR4, a receptor for CXCL12, in HSCs severely impaired HSC maintenance; thus, the cells abundantly expressing CXCL12 were identified as CXCL12-abundant reticular (CAR) cells, a critical HSC regulating stromal cell in the BM. CAR cells were found surrounding sinusoidal endothelial cells or located near the endosteum [34]. However, the identify of CAR cells as adipo-osteogenic bipotential progenitors was not uncovered until recently [35]. A genetic approach to delete $\mathrm{Cxcl12}$ from different niches revealed that both early mesenchymal progenitors and endothelial cells serve as the functional CXCL12 source for HSC maintenance. Conditional deletion of $\mathrm{Cxcl12}$ from hematopoietic cells or Nestin-expressing cells had little or no effect on HSCs or restricted progenitors. However, deletion of $\mathrm{Cxcl12}$ from osteoblasts depleted certain early lymphoid progenitors $[36,37]$. This suggests that CXCL12 secreted from distinct cellular niches in BM might have different functions.

Transforming growth factor beta 1 (TGF- $\beta 1$ ) is a secreted protein that performs many cellular functions, including the control of cell growth, cell proliferation, cell differentiation, and apoptosis [38]. TGF $\beta 1$ signaling has been identified as a critical signaling to keep HSCs in the quiescent state [39]. TGF $\beta$ receptor (Tgf $\beta r 1$ or $T g f \beta r 2)$ deficient HSCs have increased proliferation but impaired long-term self-renewal potential [40,41]. MKs have been identified as the main source of supplying TGF $\beta 1$ in BM since deleting TGF $\beta 1$ from MKs led to HSC proliferation [24]. Nonmyelinating Schwann cells (glial cells ensheathed autonomic nerves) have been identified as a critical TGF $\beta$ signal regulator which contributes to TGF $\beta$ activation and HSC maintenance in the BM [41]. This suggests that MKs and neural glial cells form a distinct niche for HSC quiescence maintenance.

The osteoblast niche in the endosteal region was the first identified HSC niche in BM, although factors from this niche contributing to HSC regulation have not yet been identified. Some researchers tended to exclude the osteoblast niche from the HSC functional supporting cells because deleting either $S c f$ or $C x c l 12$ using Col2.3-Cre did not affect HSC function in mice. However, recent evidence has shown that Col2.3-Cre induced osteoblast oblation in mice impaired HSC self-renewal function, though the overall number of HSCs did not significantly change [42,43]. This suggests that Col2.3-Cre marked osteoblasts might produce other unknown factors that contribute to maintaining HSC self-renewal potential. Indeed, angiopoietin-1 [14], thrombopoietin [28], Jagged-1 [44], and non-canonical Wnt signals [15] from the osteoblastic niche in the endosteal region have been suggested for HSC regulation. However, more direct evidence-such as the effects of directly deleting those factors from the osteoblastic niche-is still needed. Whether the widely used Col2.3-Cre line could serve the purpose to study the osteoblastic niche in the endosteal region also remains questionable. For example, using current Cre lines, researchers still could not identify the functional resource of angiopoietin 1 [45], which is known to contribute to HSC regulation in vivo [14]. Furthermore, functionally deleting critical HSC regulation factors from the perivascular niche dramatically reduces HSC abundance in the BM; however, significant functional HSC is retained [31,36,37]. Although uneven recombination efficiencies of Cre recombinase among cell types and transgenic strains explain variability in current studies, it also suggests that some important niche components may have been missed in the "taking one off" studies due to lack of appropriate genetic tools.

Although competing models still exist, researchers recently have formed a consensus that mesenchymal stem cells (MSCs) are critical for forming the HSC niche in BM. MSCs are self-renewing precursor cells that can differentiate into bone, fat, cartilage, and stromal cells of the BM. The first approach using Nestin-GFP reporter mouse line found that Nestin ${ }^{+}$MSCs are spatially associated with HSCs and highly express HSC maintenance factors, suggesting that MSCs and HSCs form a unique BM niche [46]. Researchers subsequently used different genetic approaches and demonstrated how different MSCs contribute to HSC regulation in that $\mathrm{Lepr}^{+} \mathrm{MSCs}$ and $\mathrm{Prx}^{+} \mathrm{MSC}$ supply SCF and CXCL12 respectively for HSCs maintenance and that arteriolar $\mathrm{Ng}^{+} \mathrm{MSC}$ regulate $\mathrm{HSC}$ quiescence through unknown mechanisms [22,37,47]. All $\mathrm{Lepr}^{+}, \mathrm{Nestin}^{+}, \mathrm{Prx} 1^{+}$, $\mathrm{Ng} 2^{+}$cells could behave as MSCs; however, their characterizations remain vague because it is still not clear at which 
level they overlap with each other. Furthermore, it is still difficult to conclude whether the observed influences on HSCs are due to MSCs themselves or their progenies. Future understanding of the complexity of the HSC niche will be achieved by targeting more specific niche cells. More suitable Cre lines and in-depth studies are urgently needed for future investigation of these HSC niches.

\section{Bone marrow niche signals during regenera- tion}

HSCs can switch from quiescent state to proliferating state in order to quickly recover the hematopoiesis system injured from myeloablation, hemorrhage, or inflammation stress. Several niche signals have been suggested to be involved in this HSC regeneration regulation.

Wnt signaling has been demonstrated to regulate development of various tissues. Initial $\beta$-catenin (Ctnnb1, an important component of the Wnt pathway) gain-of-function studies demonstrated that activating -catenin in HSCs promotes HSC expansion in vitro and lineage reconstitutive capacity in vivo, especially in cooperation with activation of the AKT pathway [48-50]. However, genetically deleting $\beta$-catenin from HSCs did not affect hematopoiesis after transplantation [51-53]. A recent study showed that LT-HSCs were maintained in a quiescent state by noncanonical Wnt signaling, via Frizzled $8(\mathrm{Fzd} 8)$ receptor and Flamingo (Fmi, or Celsrt) during homeostasis, which antagonized canonical Wnt signals. Chemotherapeutic stress-mediated activation of HSCs in mice resulted in repressed noncanonical Wnt signaling and enhanced canonical Wnt signaling, leading to HSC activation. Loss of $\beta$-catenin impaired HSC regeneration through enhanced oxidative stress $[15,54,55]$. All these suggest that canonical Wnt signaling can serve as a stress response signal to support HSC regeneration during stress.

Fibroblast growth factor (FGF), similar to Wnt, stimulates another signaling pathway that has been proven to promote HSC expansion in vitro [56,57]. Similarly, neither genetically deleting FGF receptor 1(Fgfr1) from HSCs nor deleting FGF2 from the niche affected HSC hematopoiesis after transplantation. However, when those FGF signal defective mice were challenged by chemotherapeutic stress, their HSC regeneration and hematopoiesis recovery were severely impaired. This can be explained by the inactive FGF signals during homeostasis with low levels of FGFs in BM and FGFRs in HSCs; however, both FGF ligands in $\mathrm{BM}$ and FGF receptors were boosted under stress to turn on FGF signals for promoting HSC proliferation through activation of $\mathrm{AKT}$ and $\mathrm{NF}-\kappa \mathrm{B}$ mechanisms. Interestingly, FGF signal was also shown to play a role in mobilizing HSCs to spleen for extramedullary hematopoiesis through regulating CXCR4-CXCL12 pathway that further facilitated HSC re- generation under stress [24,58,59].

Epidermal growth factor (EGF) signaling was also shown to promote HSC regeneration post injury, possibly through repression of the pro-apoptotic protein PUMA [60]. Deletion or blockage of the adhesion molecule E-selectin was shown to promote HSC survival and regeneration post myeloablation stress through manipulating HSC and vascular niche interaction [61]. However, the effects from EGF and E-selectin are not limited to stressed conditions, as they also contribute to HSC maintenance during homeostasis.

\section{HSC maintenance in hypoxic microenviron- ment}

An early study suggested HSCs are kept in the hypoxia microenvironment in BM [62]. Subsequent functional studies showed that HSCs have elevated levels of HIF-1 $\alpha$ (hypoxia-inducible factors-1 alpha subunit), a cellular response mediator to hypoxia. The increased HIF-1 $\alpha$ level in HSCs led to the up-regulation of HIF-1 $\alpha$ targeted genes, which controls glycolysis. As a consequence, HSCs increased the rates of glycose consumption and lactate production and decreased the rates of oxygen consumption and mitochondrial potential [63]. Consistently, HIF-1 $\alpha$ deficient HSCs lost their quiescence and long-term repopulation capacity [64]. These evidences suggest the existence of a hypoxia niche in BM that maintains the quiescence of HSCs. To search for the hypoxia zone in BM, researchers have directly measured the oxygen tension in the BM of live mice and revealed that peri-sinusoidal regions have less local oxygen tension and, by contrast, the endosteal region is less hypoxic as it is perfused with small arteries [65]. However, hypoxia signaling is a double-edged sword for HSCs. Although the elevated HIF-1 $\alpha$ level in HSCs is critical for HSC maintenance, researchers also found that overstabilization of HIF-1 $\alpha$ in HSCs by deleting Von Hippel-Lindau (VHL), an E3 ubiquitin ligase for HIF-1 $\alpha$, resulted in HSC failure to move into cell cycle and loss of reconstitution capacity [64]. This indicated that the level of the HIF-1 $\alpha$ is critical: either too high or too low will affect HSC function. The impact of hypoxia microenvironment on HSC function maintenance is still unclear. For example, HSCs often mobilize from BM to the peripheral blood, where the oxygen level is high. How HSC function is maintained in such a high oxygen microenvironment is not known. Thus, further studies are needed to understand how the functional HSCs are maintained in the hypoxia niche in BM.

\section{MK niche for HSC maintenance and regen- eration}

Recently MKs, one of the mature blood cell types, have 
been demonstrated to constitute a critical niche for HSC quiescence maintenance during homeostasis and HSC regeneration under stress. More interestingly, this MK niche also appears to contribute to the architectural maintenance of multiple stromal niches.

Multiple BM stromal cell types have been identified as HSC-regulating niche cells. It remains unclear how a feedback from mature cells is conveyed to HSCs to adjust their cell cycle stage. MKs were found associated with HSCs in a nonrandom fashion in the BM. Functional studies show that MKs are able to directly regulate HSC quiescence through multiple HSC-regulating factors including TGF $\beta$, CXCL4, and THPO [23,24,66,67]. More importantly, MKs can balance TGF- $\beta$ and FGF output, thereby regulating respectively hematopoietic homeostasis and regeneration following chemotherapeutic stress in vivo [24,68]. This suggests that MKs constitute an even more specialized HSC niche, which can control HSC cell cycle activity based on demands, serving as a sensor to guide HSC switching between quiescence and regeneration [69].

Studies also suggest that MKs have vascular and osteoblast regulatory factors that influence the number and function of both osteoblastic and vascular niches in BM. Mature MKs are primarily located adjacent to blood vessels, where they extend transendothelial pseudopods or migrate through the endothelium to produce platelets [70-72]. MKs are a major source of both pro-angiogenetic and anti-angiogenic factors, which makes them a regulator for angiogenesis and maintenance of blood vessel integrity [73-75]. MKs have also been proposed as a major regulator for HSC niche remodeling post injury. Myelosuppression destroys the entire vascular niche and damages the endosteal niche [22,76,77]; thus, BM niche reconstitution is considered critical for HSC regeneration. Interestingly, MKs were found tightly associated with BM blood vessels post chemotherapeutic stress [24,72], contributing to blood vessel recovery through thrombospondin (TSP)1, an endogenous angiogenesis inhibitor [75]. Furthermore, post total body irradiation, surviving MKs relocated to the endosteal surface of trabecular bone where MKs promoted osteoblast proliferation but inhibited osteoclast formation through producing growth factor (PDGF)- $\beta$ and FGF-2, which facilitates stem cell engraftment postirradiation [78-81].

\section{Perspective}

Recent experimentation has validated the niche concept and reinforced understanding of the structure of the molecular and cellular nature of HSC niches in BM. In the future, manipulating the stem cell niche opens the possibilities of benefiting hematopoietic maintenance and regeneration. Continued progress in heightened knowledge of the key players of HSC niches will provide exciting new avenues for improving regenerative medicine and treating hematopoietic disorders. This knowledge will also be applied to engineer ex vivo niches for HSC expansion that will facilitate stem cell therapy in clinics.

The author(s) declare that they have no conflict of interest.

1 Till JE, McCulloch EA, Siminovitch L. A stochastic model of stem cell proliferation, based on the growth of spleen colony-forming cells. Proc Natl Acad Sci USA, 1964, 51: 29-36

2 Siminovitch L, McCulloch EA, Till JE. The distribution of colony-forming cells among spleen colonies. J Cell Physiol, 1963, 62: 327-336

3 Schofield R. The relationship between the spleen colony-forming cell and the haemopoietic stem cell. Blood Cells, 1978, 4: 7-25

4 Dexter TM, Allen TD, Lajtha LG. Conditions controlling the proliferation of haemopoietic stem cells in vitro. J Cell Physiol, 1977, 91: 335-344

5 Taichman RS, Emerson SG. Human osteoblasts support hematopoiesis through the production of granulocyte colony-stimulating factor. J Exp Med, 1994, 179: 1677-1682

6 Calvi LM, Adams GB, Weibrecht KW, Weber JM, Olson DP, Knight MC, Martin RP, Schipani E, Divieti P, Bringhurst FR, Milner LA, Kronenberg HM, Scadden DT. Osteoblastic cells regulate the haematopoietic stem cell niche. Nature, 2003, 425: 841-846

7 Zhang J, Niu C, Ye L, Huang H, He X, Tong WG, Ross J, Haug J, Johnson T, Feng JQ, Harris S, Wiedemann LM, Mishina Y, Li L. Identification of the haematopoietic stem cell niche and control of the niche size. Nature, 2003, 425: 836-841

8 Kiel MJ, Yilmaz OH, Iwashita T, Terhorst C, Morrison SJ. Slam family receptors distinguish hematopoietic stem and progenitor cells and reveal endothelial niches for stem cells. Cell, 2005, 121: 1109-1121

9 Morrison SJ, Scadden DT. The bone marrow niche for haematopoietic stem cells. Nature, 2014, 505: 327-334

10 Mendez-Ferrer S, Scadden DT, Sanchez-Aguilera A. Bone marrow stem cells: current and emerging concepts. Ann N Y Acad Sci, 2015, 1335: 32-44

11 Wilson A, Laurenti E, Oser G, van der Wath RC, Blanco-Bose W, Jaworski M, Offner S, Dunant CF, Eshkind L, Bockamp E, Lio P, Macdonald HR, Trumpp A. Hematopoietic stem cells reversibly switch from dormancy to self-renewal during homeostasis and repair. Cell, 2008, 135: 1118-1129

12 Cheng T, Rodrigues N, Shen H, Yang Y, Dombkowski D, Sykes M, Scadden DT. Hematopoietic stem cell quiescence maintained by p21cip1/waf1. Science, 2000, 287: 1804-1808

13 Ogawa M. Differentiation and proliferation of hematopoietic stem cells. Blood, 1993, 81: 2844-2853

14 Arai F, Hirao A, Ohmura M, Sato H, Matsuoka S, Takubo K, Ito K, Koh GY, Suda T. Tie2/angiopoietin-1 signaling regulates hematopoietic stem cell quiescence in the bone marrow niche. Cell, 2004, 118: 149-161

15 Sugimura R, He XC, Venkatraman A, Arai F, Box A, Semerad C, Haug JS, Peng L, Zhong XB, Suda T, Li L. Noncanonical wnt signaling maintains hematopoietic stem cells in the niche. Cell, 2012, 150: 351-365

16 Foudi A, Hochedlinger K, Van Buren D, Schindler JW, Jaenisch R, Carey V, Hock H. Analysis of histone 2B-GFP retention reveals slowly cycling hematopoietic stem cells. Nat Biotechnol, 2008, 27: 84-90

17 Sprent J, Tough DF. Lymphocyte life-span and memory. Science, 1994, 265: 1395-1400

18 Xie Y, Yin T, Wiegraebe W, He XC, Miller D, Stark D, Perko K, Alexander R, Schwartz J, Grindley JC, Park J, Haug JS, Wunderlich JP, Li H, Zhang S, Johnson T, Feldman RA, Li L. Detection of functional haematopoietic stem cell niche using real-time imaging. Nature, 2009, 457: 97-101 
19 Lo Celso C, Fleming HE, Wu JW, Zhao CX, Miake-Lye S, Fujisaki J, Cote D, Rowe DW, Lin CP, Scadden DT. Live-animal tracking of individual haematopoietic stem/progenitor cells in their niche. Nature, 2009, 457: 92-96

20 Nombela-Arrieta C, Pivarnik G, Winkel B, Canty KJ, Harley B, Mahoney JE, Park SY, Lu J, Protopopov A, Silberstein LE. Quantitative imaging of haematopoietic stem and progenitor cell localization and hypoxic status in the bone marrow microenvironment. Nat Cell Biol, 2013, 15: 533-543

21 Weksberg DC, Chambers SM, Boles NC, Goodell MA. Cd150- side population cells represent a functionally distinct population of long-term hematopoietic stem cells. Blood, 2008, 111: 2444-2451

22 Kunisaki Y, Bruns I, Scheiermann C, Ahmed J, Pinho S, Zhang D, Mizoguchi T, Wei Q, Lucas D, Ito K, Mar JC, Bergman A, Frenette PS. Arteriolar niches maintain haematopoietic stem cell quiescence. Nature, 2013, 502: 637-643

23 Bruns I, Lucas D, Pinho S, Ahmed J, Lambert MP, Kunisaki Y, Scheiermann C, Schiff L, Poncz M, Bergman A, Frenette PS. Megakaryocytes regulate hematopoietic stem cell quiescence through CXCL4 secretion. Nat Med, 2014, 20: 1315-1320

24 Zhao M, Perry JM, Marshall H, Venkatraman A, Qian P, He XC, Ahamed J, Li L. Megakaryocytes maintain homeostatic quiescence and promote post-injury regeneration of hematopoietic stem cells. Nat Med, 2014, 20: 1321-1326

25 Scadden DT. The stem-cell niche as an entity of action. Nature, 2006, 441: 1075-1079

26 Wilson A, Trumpp A. Bone-marrow haematopoietic-stem-cell niches. Nat Rev Immunol, 2006, 6: 93-106

27 Kollet O, Dar A, Shivtiel S, Kalinkovich A, Lapid K, Sztainberg Y, Tesio M, Samstein RM, Goichberg P, Spiegel A, Elson A, Lapidot T. Osteoclasts degrade endosteal components and promote mobilization of hematopoietic progenitor cells. Nat Med, 2006, 12: 657-664

28 Yoshihara H, Arai F, Hosokawa K, Hagiwara T, Takubo K, Nakamura Y, Gomei Y, Iwasaki H, Matsuoka S, Miyamoto K, Miyazaki H, Takahashi T, Suda T. Thrombopoietin/mpl signaling regulates hematopoietic stem cell quiescence and interaction with the osteoblastic niche. Cell Stem Cell, 2007, 1: 685-697

29 Kent D, Copley M, Benz C, Dykstra B, Bowie M, Eaves C. Regulation of hematopoietic stem cells by the steel factor/kit signaling pathway. Clin Cancer Res, 2008, 14: 1926-1930

30 Broudy VC. Stem cell factor and hematopoiesis. Blood, 1997, 90: 1345-1364

31 Ding L, Saunders TL, Enikolopov G, Morrison SJ. Endothelial and perivascular cells maintain haematopoietic stem cells. Nature, 2012, 481: 457-462

32 Ma Q, Jones D, Borghesani PR, Segal RA, Nagasawa T, Kishimoto T, Bronson RT, Springer TA. Impaired b-lymphopoiesis, myelopoiesis, and derailed cerebellar neuron migration in CXCR4- and SDF-1deficient mice. Proc Natl Acad Sci USA, 1998, 95: 9448-9453

33 Levesque JP, Hendy J, Takamatsu Y, Simmons PJ, Bendall LJ. Disruption of the CXCR4/CXCL12 chemotactic interaction during hematopoietic stem cell mobilization induced by GCSF or cyclophosphamide. J Clin Invest, 2003, 111: 187-196

34 Sugiyama T, Kohara H, Noda M, Nagasawa T. Maintenance of the hematopoietic stem cell pool by CXCL12-CXCR4 chemokine signaling in bone marrow stromal cell niches. Immunity, 2006, 25: 977-988

35 Omatsu Y, Seike M, Sugiyama T, Kume T, Nagasawa T. Foxc1 is a critical regulator of haematopoietic stem/progenitor cell niche formation. Nature, 2014, 508: 536-540

36 Ding L, Morrison SJ. Haematopoietic stem cells and early lymphoid progenitors occupy distinct bone marrow niches. Nature, 2013, 495: 231-235

37 Greenbaum A, Hsu YM, Day RB, Schuettpelz LG, Christopher MJ, Borgerding JN, Nagasawa T, Link DC. CXCL12 in early mesenchymal progenitors is required for haematopoietic stem-cell maintenance. Nature, 2013, 495: 227-230

38 Massague J. TGFbeta signalling in context. Nat Rev, 2012, 13: 616-630
39 Yamazaki S, Iwama A, Takayanagi S, Eto K, Ema H, Nakauchi H. TGF-beta as a candidate bone marrow niche signal to induce hematopoietic stem cell hibernation. Blood, 2009, 113: 1250-1256

40 Larsson J, Blank U, Helgadottir H, Bjornsson JM, Ehinger M, Goumans MJ, Fan X, Leveen P, Karlsson S. TGF-beta signaling-deficient hematopoietic stem cells have normal self-renewal and regenerative ability in vivo despite increased proliferative capacity in vitro. Blood, 2003, 102: 3129-3135

41 Yamazaki S, Ema H, Karlsson G, Yamaguchi T, Miyoshi H, Shioda S, Taketo MM, Karlsson S, Iwama A, Nakauchi H. Nonmyelinating schwann cells maintain hematopoietic stem cell hibernation in the bone marrow niche. Cell, 2011, 147: 1146-1158

42 Zhao M, Li L. Osteoblast ablation burns out functional stem cells. Blood, 2015, 125: 2590-2591

43 Bowers M, Zhang B, Ho Y, Agarwal P, Chen CC, Bhatia R. Osteoblast ablation reduces normal long-term hematopoietic stem cell self-renewal but accelerates leukemia development. Blood, 2015, 125: 2678-2688

44 Guezguez B, Campbell CJ, Boyd AL, Karanu F, Casado FL, Di Cresce C, Collins TJ, Shapovalova Z, Xenocostas A, Bhatia M. Regional localization within the bone marrow influences the functional capacity of human HSCs. Cell Stem Cell, 2013, 13: 175-189

45 Zhou BO, Ding L, Morrison SJ. Hematopoietic stem and progenitor cells regulate the regeneration of their niche by secreting angiopoietin-1. ELife, 2015, 4: e05521

46 Mendez-Ferrer S, Michurina TV, Ferraro F, Mazloom AR, Macarthur BD, Lira SA, Scadden DT, Ma'ayan A, Enikolopov GN, Frenette PS. Mesenchymal and haematopoietic stem cells form a unique bone marrow niche. Nature, 2010, 466: 829-834

47 Zhou BO, Yue R, Murphy MM, Peyer JG, Morrison SJ. Leptin-receptor-expressing mesenchymal stromal cells represent the main source of bone formed by adult bone marrow. Cell Stem Cell, 2014, 15: $154-168$

48 Reya T, Duncan AW, Ailles L, Domen J, Scherer DC, Willert K, Hintz L, Nusse R, Weissman IL. A role for Wnt signalling in self-renewal of haematopoietic stem cells. Nature, 2003, 423: $409-414$

49 Willert K, Brown JD, Danenberg E, Duncan AW, Weissman IL, Reya T, Yates JR 3rd, Nusse R. Wnt proteins are lipid-modified and can act as stem cell growth factors. Nature, 2003, 423: 448-452

50 Perry JM, He XC, Sugimura R, Grindley JC, Haug JS, Ding S, Li L. Cooperation between both $\mathrm{Wnt} /\{$ beta $\}$-catenin and pten/pi3k/akt signaling promotes primitive hematopoietic stem cell self-renewal and expansion. Genes Dev, 2011, 25: 1928-1942

51 Koch U, Wilson A, Cobas M, Kemler R, Macdonald HR, Radtke F. Simultaneous loss of beta- and gamma-catenin does not perturb hematopoiesis or lymphopoiesis. Blood, 2008, 111: 160-164

52 Jeannet G, Scheller M, Scarpellino L, Duboux S, Gardiol N, Back J, Kuttler F, Malanchi I, Birchmeier W, Leutz A, Huelsken J, Held W. Long-term, multilineage hematopoiesis occurs in the combined absence of $\{$ beta $\}$-catenin and \{gamma\}-catenin. Blood, 2008, 111: 142-149

53 Cobas M, Wilson A, Ernst B, Mancini SJ, MacDonald HR, Kemler $\mathrm{R}$, Radtke F. Beta-catenin is dispensable for hematopoiesis and lymphopoiesis. J Exp Med, 2004, 199: 221-229

54 Nemeth MJ, Topol L, Anderson SM, Yang Y, Bodine DM. Wnt5a inhibits canonical Wnt signaling in hematopoietic stem cells and enhances repopulation. Proc Natl Acad Sci USA, 2007, 104: 15436-15441

55 Lento W, Ito T, Zhao C, Harris JR, Huang W, Jiang C, Owzar K, Piryani S, Racioppi L, Chao N, Reya T. Loss of beta-catenin triggers oxidative stress and impairs hematopoietic regeneration. Genes Dev, 2014, 28: 995-1004

56 de Haan G, Weersing E, Dontje B, van Os R, Bystrykh LV, Vellenga $\mathrm{E}$, Miller $\mathrm{G}$. In vitro generation of long-term repopulating hematopoietic stem cells by fibroblast growth factor-1. Dev Cell, 2003, 4: 241-251

57 Zhang CC, Lodish HF. Murine hematopoietic stem cells change their surface phenotype during ex vivo expansion. Blood, 2005, 105: 
4314-4320

58 Zhao M, Ross JT, Itkin T, Perry JM, Venkatraman A, Haug JS, Hembree MJ, Deng CX, Lapidot T, He XC, Li L. FGF signaling facilitates postinjury recovery of mouse hematopoietic system. Blood, 2012, 120: 1831-1842

59 Itkin T, Ludin A, Gradus B, Gur-Cohen S, Kalinkovich A, Schajnovitz A, Ovadya Y, Kollet O, Canaani J, Shezen E, Coffin DJ, Enikolopov GN, Berg T, Piacibello W, Hornstein E, Lapidot T. FGF-2 expands murine hematopoietic stem and progenitor cells via proliferation of stromal cells, c-kit activation, and CXCL12 down-regulation. Blood, 2012, 120: 1843-1855

60 Doan PL, Himburg HA, Helms K, Russell JL, Fixsen E, Quarmyne M, Harris JR, Deoliviera D, Sullivan JM, Chao NJ, Kirsch DG, Chute JP. Epidermal growth factor regulates hematopoietic regeneration after radiation injury. Nat Med, 2013, 19: 295-304

61 Winkler IG, Barbier V, Nowlan B, Jacobsen RN, Forristal CE, Patton JT, Magnani JL, Levesque JP. Vascular niche e-selectin regulates hematopoietic stem cell dormancy, self renewal and chemoresistance. Nat Med, 2012, 18: 1651-1657

62 Parmar K, Mauch P, Vergilio JA, Sackstein R, Down JD. Distribution of hematopoietic stem cells in the bone marrow according to regional hypoxia. Proc Natl Acad Sci USA, 2007, 104: 5431-5436

63 Simsek T, Kocabas F, Zheng J, Deberardinis RJ, Mahmoud AI, Olson EN, Schneider JW, Zhang CC, Sadek HA. The distinct metabolic profile of hematopoietic stem cells reflects their location in a hypoxic niche. Cell Stem Cell, 2010, 7: 380-390

64 Takubo K, Goda N, Yamada W, Iriuchishima H, Ikeda E, Kubota Y, Shima H, Johnson RS, Hirao A, Suematsu M, Suda T. Regulation of the HIF-1alpha level is essential for hematopoietic stem cells. Cell Stem Cell, 2010, 7: 391-402

65 Spencer JA, Ferraro F, Roussakis E, Klein A, Wu J, Runnels JM, Zaher W, Mortensen LJ, Alt C, Turcotte R, Yusuf R, Cote D, Vinogradov SA, Scadden DT, Lin CP. Direct measurement of local oxygen concentration in the bone marrow of live animals. Nature, 2014, 508: 269-273

66 Nakamura-Ishizu A, Takubo K, Fujioka M, Suda T. Megakaryocytes are essential for HSC quiescence through the production of thrombopoietin. Biochem Biophys Res Commun, 2014, 454: 353-357

67 Heazlewood SY, Neaves RJ, Williams B, Haylock DN, Adams TE, Nilsson SK. Megakaryocytes co-localise with hemopoietic stem cells and release cytokines that up-regulate stem cell proliferation. Stem Cell Res, 2013, 11: 782-792

68 Blank U, Karlsson S. TGF-beta signaling in the control of hematopoietic stem cells. Blood, 2015, 125: 3542-3550

69 Schepers K, Campbell TB, Passegue E. Normal and leukemic stem cell niches: insights and therapeutic opportunities. Cell Stem Cell, 2015, 16: 254-267

70 Wang JF, Liu ZY, Groopman JE. The alpha-chemokine receptor
CXCR4 is expressed on the megakaryocytic lineage from progenitor to platelets and modulates migration and adhesion. Blood, 1998, 92: 756-764

71 Hamada T, Mohle R, Hesselgesser J, Hoxie J, Nachman RL, Moore MA, Rafii S. Transendothelial migration of megakaryocytes in response to stromal cell-derived factor 1 (SDF-1) enhances platelet formation. J Exp Med, 1998, 188: 539-548

72 Avecilla ST, Hattori K, Heissig B, Tejada R, Liao F, Shido K, Jin DK, Dias S, Zhang F, Hartman TE, Hackett NR, Crystal RG, Witte L, Hicklin DJ, Bohlen P, Eaton D, Lyden D, de Sauvage F, Rafii S. Chemokine-mediated interaction of hematopoietic progenitors with the bone marrow vascular niche is required for thrombopoiesis. Nat Med, 2004, 10: 64-71

73 Mohle R, Green D, Moore MA, Nachman RL, Rafii S. Constitutive production and thrombin-induced release of vascular endothelial growth factor by human megakaryocytes and platelets. Proc Natl Acad Sci USA, 1997, 94: 663-668

74 Varner JA. The sticky truth about angiogenesis and thrombospondins. J Clin Invest, 2006, 116: 3111-3113

75 Kopp HG, Hooper AT, Broekman MJ, Avecilla ST, Petit I, Luo M, Milde T, Ramos CA, Zhang F, Kopp T, Bornstein P, Jin DK, Marcus AJ, Rafii S. Thrombospondins deployed by thrombopoietic cells determine angiogenic switch and extent of revascularization. J Clin Invest, 2006, 116: 3277-3291

76 Hooper AT, Butler JM, Nolan DJ, Kranz A, Iida K, Kobayashi M, Kopp HG, Shido K, Petit I, Yanger K, James D, Witte L, Zhu Z, Wu Y, Pytowski B, Rosenwaks Z, Mittal V, Sato TN, Rafii S. Engraftment and reconstitution of hematopoiesis is dependent on VEGFR2-mediated regeneration of sinusoidal endothelial cells. Cell Stem Cell, 2009, 4: 263-274

77 Jiang Y, Bonig H, Ulyanova T, Chang K, Papayannopoulou T. On the adaptation of endosteal stem cell niche function in response to stress. Blood, 2009, 114: 3773-3782

78 Ciovacco WA, Cheng YH, Horowitz MC, Kacena MA. Immature and mature megakaryocytes enhance osteoblast proliferation and inhibit osteoclast formation. J Cell Biochem, 2010, 109: 774-781

79 Beeton CA, Bord S, Ireland D, Compston JE. Osteoclast formation and bone resorption are inhibited by megakaryocytes. Bone, 2006, 39: 985-990

80 Olson TS, Caselli A, Otsuru S, Hofmann TJ, Williams R, Paolucci P, Dominici M, Horwitz EM. Megakaryocytes promote murine osteoblastic hsc niche expansion and stem cell engraftment after radioablative conditioning. Blood, 2013, 121: 5238-5249

81 Dominici M, Rasini V, Bussolari R, Chen X, Hofmann TJ, Spano C, Bernabei D, Veronesi E, Bertoni F, Paolucci P, Conte P, Horwitz EM. Restoration and reversible expansion of the osteoblastic hematopoietic stem cell niche after marrow radioablation. Blood, 2009, 114: 2333-2343

Open Access This article is distributed under the terms of the Creative Commons Attribution License which permits any use, distribution, and reproduction in any medium, provided the original author(s) and source are credited. 